Article

\title{
Catalytic Copyrolysis of Cork Oak and Waste Plastic Films over HBeta
}

\author{
Young-Kwon Park ${ }^{1}$, Boram Lee ${ }^{2}$, Atsushi Watanabe ${ }^{3}$, Hyung Won Lee ${ }^{1}$ (iD, Ji Young Lee ${ }^{1,4}$ (iD, \\ Seungdo Kim ${ }^{2}$, Tae Uk Han ${ }^{2}$ and Young-Min Kim ${ }^{2, *}$ \\ 1 School of Environmental Engineering, University of Seoul, Seoul 02504, Korea; catalica@uos.ac.kr (Y.-K.P.); \\ adexhw@nate.com (H.W.L.); flyjiyoung@kitech.re.kr (J.Y.L.) \\ 2 Department of Environmental Sciences and Biotechnology, Hallym University, Chuncheon 24252, Korea; \\ dlqhfka511@naver.com (B.L.); sdkim@hallym.ac.kr (S.K.); taeukhan@naver.com (T.U.H.) \\ 3 Frontier Laboratories Ltd., 4-16-20, Saikon, Koriyama, Fukushima 963-8862, Japan; ichi@frontier-lab.com \\ 4 Korea National Industrial Convergence Center, Korea Institute of Industrial Technology, Ansan 15588, Korea \\ * Correspondence: analyst@hallym.ac.kr; Tel.: +82-33-248-3324
}

Received: 13 July 2018; Accepted: 1 August 2018; Published: 3 August 2018

check for updates

\begin{abstract}
The catalytic fast copyrolysis (CFCP) of cork oak (CoOak) and waste plastic films (WPFs) over $\mathrm{HBeta}(25)\left(\mathrm{SiO}_{2} / \mathrm{Al}_{2} \mathrm{O}_{3}\right.$ : 25) was investigated using a thermogravimetric (TG) analyzer and a tandem micro reactor-gas chromatography/mass spectrometry (TMR-GC/MS) to determine the effectiveness of WPFs as the hydrogen donating cofeeding feedstock on the CFCP of biomass. By applying CFCP, the maximum decomposition temperatures of CoOak $\left(373.4^{\circ} \mathrm{C}\right)$ and WPFs $\left(487.9^{\circ} \mathrm{C}\right.$ ) were reduced to $364.5^{\circ} \mathrm{C}$ for CoOak and $436.5^{\circ} \mathrm{C}$ for WPFs due to the effective interaction between the pyrolysis intermediates of CoOak and WPFs over HBeta(25), which has strong acidity and an appropriate pore size. The experimental yields of aromatic hydrocarbons on the CFCP of CoOak and WPFs were higher than their calculated yields concluded from the yields obtained from the individual catalytic fast pyrolysis (CFP) of CoOak and WPFs. The coke amount produced from the CFP of CoOak and WPFs over HBeta(25) were also decreased by applying CFCP.
\end{abstract}

Keywords: catalytic copyrolysis; biomass; waste plastic films; HBeta(25)

\section{Introduction}

The importance of eco-friendly renewable energy is being emphasized due to the energy crisis, increased environmental contamination, and climate change. Among the various renewable energy sources available, biomass is considered as an important material that can produce chemical feedstock because it is the only renewable carbon source in nature. To increase the value of biomass as a source for the production of energy or chemical feedstock, various kinds of thermochemical conversion technologies have been investigated worldwide [1-3].

Pyrolysis is a thermochemical conversion process that is suitable for bio-oil production from biomass. Although large amount of liquid product can be obtained from the pyrolysis of biomass due to the intensive studies over the last few decades, its actual commercial use is still limited because of its low quality and instability. Biomass pyrolysis oil has a high oxygen content because large amounts of oxygenates, such as acids, furans, ketones, aldehydes, and phenols, are produced by the primary decomposition of lignocellulosic biomass components (hemicellulose, cellulose, and lignin) [4,5]. The low heating value and high viscosity and acidity of biomass pyrolysis oil make it difficult to be used as a fuel because the direct use of biomass pyrolysis oil to engine can make the problems related with fuel injection system, such as corrosion and clogging [6].

The catalytic fast pyrolysis (CFP) of biomass has been considered as a desirable way to overcome the limited use of biomass pyrolysis oil by upgrading the quality of biomass pyrolysis oil. One of main 
purposes of the CFP of biomass is to increase aromatic hydrocarbons with high commercial value. Although various kinds of microporous and mesoporous catalysts have been applied to the CFP of biomass, the yields of aromatic hydrocarbons are still unsatisfactory and rapid catalyst deactivation is a problem limiting its actual commercialization [7-10].

To produce much larger amount of aromatic hydrocarbons on the CFP of biomass, several studies have focused on the catalytic fast copyrolysis (CFCP) of biomass and plastic materials [11]. By adding plastics, such as polyethylene (PE), polypropylene (PP), polystyrene (PS), and so on, as the cofeeding material of biomass, the yields of aromatics can be enhanced because these plastics can act as hydrogen donor to hydrogen deficient biomass. Effective aromatization between the pyrolyzates of biomass and plastics can produce the much larger amount of aromatic hydrocarbons and reduce the coke amount. A decreased coke yield can be expected by applying the CFCP of biomass and plastics, which is meaningful because the total life time of the catalysts can also be increased due to the decreased coke yield [12].

Waste plastic films (WPFs) are made from various kinds of polymer resin, such as PE, PP, PS, and polyvinylchloride (PVC), depending on its purpose. Recently, the amount of bioplastics made by blending biomass and synthetic polymer resin has also increased due to the demand for eco-friendly products. Although the recycling of WPFs is being emphasized, it is difficult because WPFs also contains various types of polymeric materials. The pyrolysis of waste plastics is a candidate method not only for its treatment, but also for the production of hydrocarbons [13-15]. On the other hand, the formation of wax, mainly from the pyrolysis of PE and PP in waste plastics, is a problem in this process because the wax product can foul and block the oil condensing line in the reactor. Therefore, in plastic pyrolysis, the catalytic upgrading process is also essential for converting this wax to low molecular hydrocarbons via an additional cracking reaction. This study, focused on the possible use of WPFs as a cofeeding material on the CFCP of biomass because they also contain large amounts of carbon and hydrogen as the main elements and can act as a hydrogen donating feedstock during the CFP of biomass. For the CFCP of biomass and plastics, HZSM-5 having 3 dimensional micropore structure was widely applied on the production of aromatic hydrocarbons via the CFCP of biomass and waste plastics $[12,15]$. HBeta is a different kind of 3-dimensional microporous zeolite consisted with two 12 member ring channels $(0.66 \times 0.67 \mathrm{~nm}$ and $0.56 \times 0.56 \mathrm{~nm})$ [16]. Owing to the proper micropore structure and high acidity of HBeta for the formation of aromatic hydrocarbons, it was used as the catalyst on the catalytic pyrolysis of plastics [17] or biomass [9,18]. However, its use on the CFCP of biomass and plastics was limited.

Therefore, the in situ CFCP of cork oak (CoOak) and WPFs over HBeta(25) $\left(\mathrm{SiO}_{2} / \mathrm{Al}_{2} \mathrm{O}_{3}: 25\right)$ was investigated to determine the effectiveness of WPFs as a cofeeding material and HBeta(25) as a catalyst. Non-isothermal decomposition behaviors of thermal and catalytic pyrolysis of CoOak, WPFs, and their mixture were examined by thermogravimetric (TG) analysis. Tandem microreactor (TMR)-gas chromatography/mass spectrometry (GC/MS) analysis was also used to determine the product property of each pyrolysis reaction. The yields of aromatic hydrocarbons from the CFCP were estimated to identify the synergistic effects of cofeeding WPFs on the CFP of CoOak.

\section{Results and Discussion}

\subsection{TG Analysis}

Figure 1 shows the derivative TG (DTG) curves for the thermal and catalytic TG analysis of CoOak, WPFs, and their mixture at $20^{\circ} \mathrm{C} / \mathrm{min}$, respectively. The DTG curve of CoOak, as shown in Figure 1a, revealed the typical DTG curve shape of wood biomass, which is consistent with the decomposition of hemicellulose, cellulose, and lignin [19]. The initial left shoulder and major sharp peaks on the DTG curve of CoOak can be assigned to the decomposition of hemicellulose and cellulose [20]. The right tailed peak was attributed to the decomposition of lignin and char stabilization [21]. The catalytic DTG curve of CoOak over HBeta(25) had the same peak shape and its decomposition temperature $\left(\mathrm{T}_{\max }\right.$, 
$\left.374.5^{\circ} \mathrm{C}\right)$ was similar to that $\left(\mathrm{T}_{\max }, 373.4^{\circ} \mathrm{C}\right)$ of the thermal DTG curve of CoOak. This indicates that the catalytic reaction is related to the upgrading of the primary product vapors of biomass [22].

The DTG curve of WPFs revealed two decomposition temperature regions, as shown in Figure $1 \mathrm{~b}$. The first decomposition peak on the DTG curve of WPFs had a similar decomposition temperature region (between 200 and $380{ }^{\circ} \mathrm{C}$ ) to that of CoOak, but, its $\mathrm{T}_{\max } 1\left(349.5^{\circ} \mathrm{C}\right)$ was different from that of CoOak $\left(374.5^{\circ} \mathrm{C}\right)$. This indicates that the polymeric material decomposed from WPFs at this temperature zone is not hemicellulose or cellulose, which are the main biopolymer components of CoOak. One of possible materials decomposed from WPFs in the low temperature zone is starch. Starch is used widely as the main raw material for biodegradable plastics and decomposed at a similar temperature region with the first DTG curve of WPFs [23]. Another raw material most commonly used for a biodegradable WPFs is thermoplastics, such as PE, PP, PS, and polyethylene terephthalate (PET) [24]. Therefore, the second DTG curve of WPFs is made by the overlapping decomposition of these thermoplastics. Although high density PE (HDPE) can be regarded as the main polymer decomposed at the maximum decomposition temperature, $\mathrm{T}_{\max } 2$ on the DTG curve of WPFs was lower than that of HDPE (Supplementary Materials Figure S1). The lower decomposition temperature of HDPE in WPFs can be explained by the radical interaction between the pyrolysis intermediates of the other polymers in WPFs. For example, the decomposition of PS and PP, having lower thermal stability than HDPE, was initiated at a lower temperature than HDPE. Moreover, the pyrolysis intermediates of PS and PP allow the decomposition of HDPE to begin at lower temperatures. Yu et al. [25] also reported that the decomposition temperatures of the polymer can be decreased when they are copyrolyzed with other polymers due to the effective radical interaction between the pyrolysis reaction intermediates. Similar thermal properties to WPFs were also reported on the TG analysis of bio-based plastics. For the production of bioplastics, maleic anhydride PE [26] or PP [27] were used to produce effective cross-linking between the hydrophilic biomass and hydrophobic plastics, and the decomposition temperatures of the plastics in the bioplastics were lower than the pure plastics because radical formation from the decomposition of the cross-linking agent affect the decomposition of the main plastic polymers [28]. Although the decomposition temperature of starch $\left(\mathrm{T}_{\max }: 349.5^{\circ} \mathrm{C}\right)$ was not changed, that of the thermoplastic resins in WPFs was shifted to a much lower temperature $\left(464.0^{\circ} \mathrm{C}\right)$ using HBeta(25). This means that the thermoplastics in WPFs are strongly influenced by the catalysts. Thermoplastics, such as PS, PP, and HDPE, can be decomposed more efficiently on the surface and pores of acid catalysts and its efficiency is related to the high acidity and appropriate pore size, which can allow the high diffusion efficiency of reactant molecules into the pore of catalyst. Marcillar et al. [29] also found the decreased decomposition temperature of PE by the use of HBeta zeolite using a TG analyzer and explained the catalytic effect is related with the external acid sites present in HBeta and its proper pore size. They explained that PE is melt during its non-isothermal heating and decomposed at the lower temperature by the efficient contact between PE molecules and the external sites of HBeta. Therefore, the decomposition of larger molecular polymers in WPFs could be enhanced by external acid sites of HBeta. Also, the efficient contact between smaller thermoplastic molecules and strong acid sites of internal pore may increase the decomposition rate of thermoplastics.

The TG curve of CoOak/WPFs mixture, Figure 1c, revealed the merged DTG peak shape of CoOak and WPFs, but, the peak temperatures of cellulose and HDPE were shifted to lower temperatures than those observed on the DTG curves of CoOak and WPFs, respectively. These also indicate that there is a mutual interaction between the pyrolyzates of CoOak and WPFs, and this mutual interaction lowers the decomposition temperature of the polymers in the mixture of CoOak and WPFs. The decomposition temperatures of the polymers in the CoOak and WPFs mixture were lower than those observed on the catalytic DTG of CoOak and WPFs, respectively. This suggests that the cofeeding of WPFs with CoOak can enhance the effects on the acceleration of polymer decomposition during CFCP over HBeta(25) due to the catalytic effect of $\operatorname{HBeta}(25)$ and the efficient interactions between the catalytic reaction intermediates of the polymers in the mixed sample. 


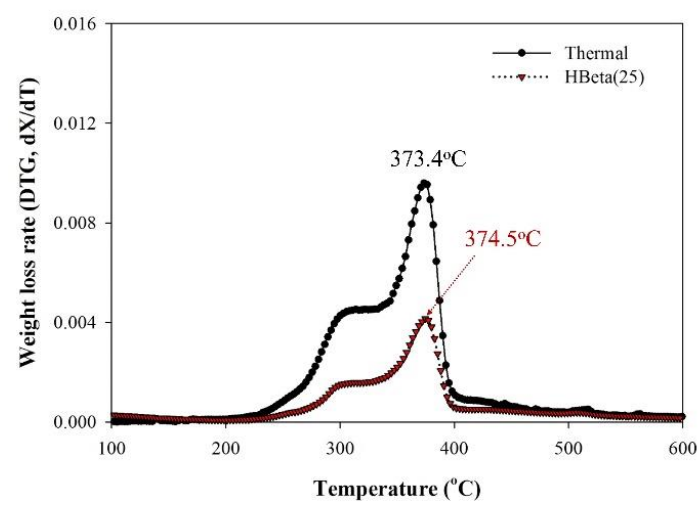

(a) CoOak

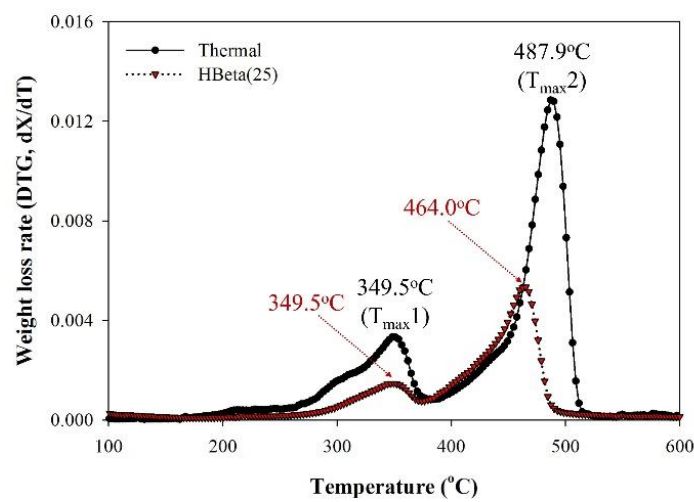

(b) WPFs

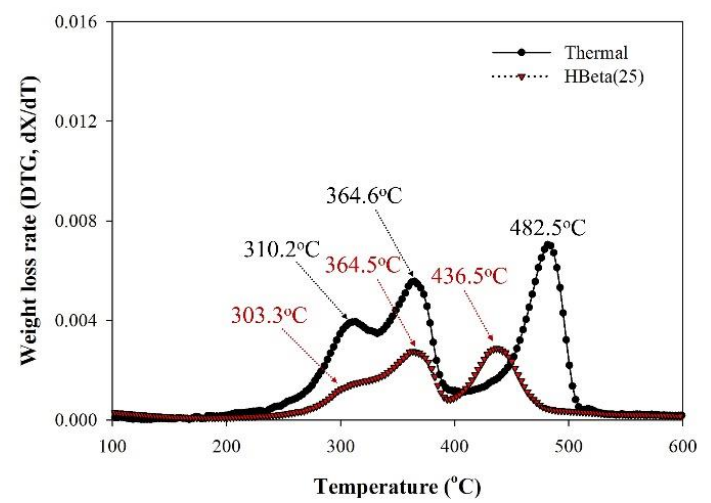

(c) $\mathrm{CoOak} / \mathrm{WPFs}$

Figure 1. DTG curves obtained from thermal and catalytic pyrolysis of (a) CoOak; (b) WPFs; and (c) CoOak/WPFs over HBeta(25).

\section{2. $T M R-G C / M S / F I D$}

\subsubsection{Non-Catalytic Pyrolysis of CoOak, WPFs, and CoOak/WPFs}

Figure 2 shows the TMR-GC/MS chromatograms obtained from the pyrolysis of CoOak, WPFs, and CoOak/WPFs. As expected, the thermal decomposition of CoOak (Figure 2a) produced large quantities of oxygen containing pyrolyzates (acetic acid, levoglucosan, guaiacols, syringols, eugenol, and so on), due to the decomposition of the lignocellulosic components of wood biomass $[19,21]$. In the case of the thermal decomposition of WPFs (Figure 2b), specific pyrolyzates of plastic resins, such as styrene monomer, dimer, and trimer of PS, alkadienes, alkenes, and alkanes in wide carbon 
range up to $\mathrm{C}_{44}$ of $\mathrm{PE}$, and 2,4-dimethyl-1-heptane of $\mathrm{PP}$, were mainly detected on the chromatogram. Although levoglucosan was observed, other typical pyrolyzates of wood biomass were not detected on the chromatogram. Possible explanation for this levoglucosan peak without other typical pyrolyzates of wood can indicate the presence of starch in WPFs. Starch can be decomposed at between 200 and $370{ }^{\circ} \mathrm{C}$ [23], which is the same decomposition on the first DTG peak of WPFs shown in Figure $1 \mathrm{~b}$, and produce levoglucosan by rapid pyrolysis [30]. The phthalate peak on the chromatogram indicates than phthalate was used as an additive of polymers in WPFs. Although the decomposition temperatures of CoOak and WPFs were shifted to a lower temperature by copyrolysis, as shown in Figure 1c, the pyrolyzates of CoOak and WPFs were not changed, as shown in Figure 2c. This means that the copyrolysis of CoOak and WPFs can allow the acceleration of polymer decomposition through a mutual interaction, but their pyrolysis products were not changed noticeably.

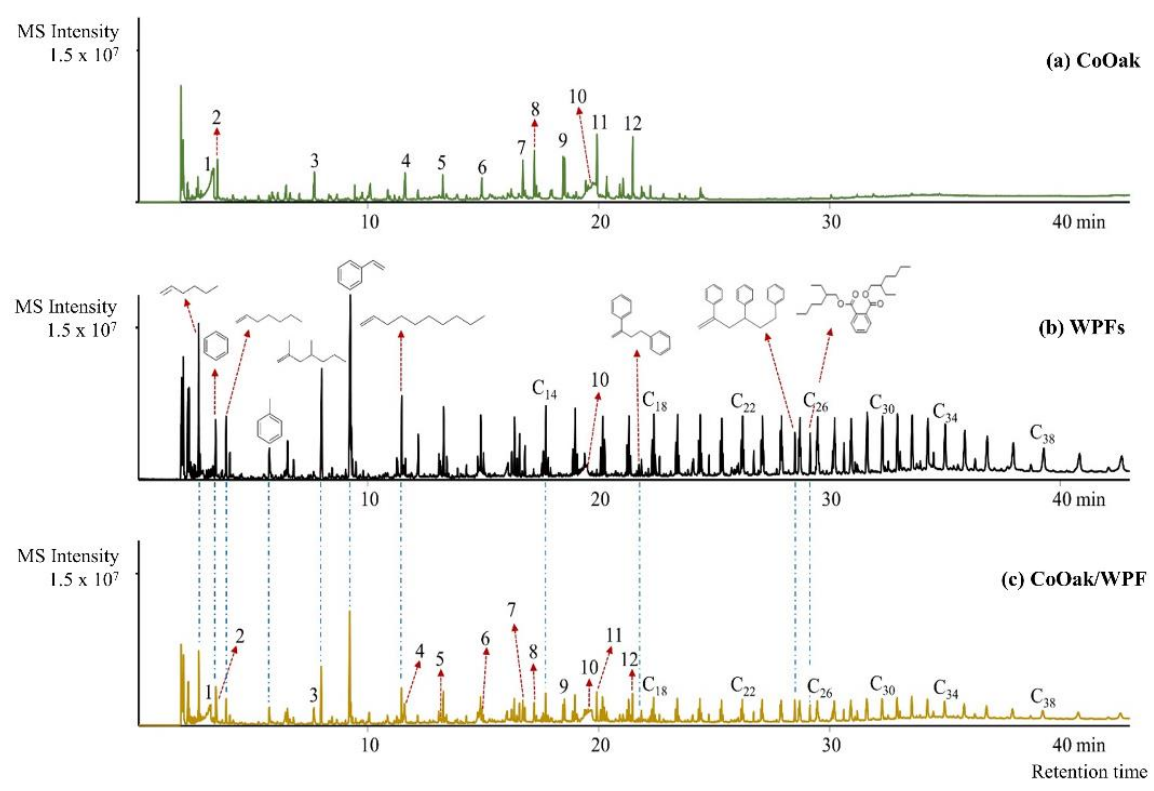

Figure 2. Pyrograms obtained from non-catalytic pyrolysis of (a) CoOak; (b) WPFS; and (c) CoOak/WPFS. (1: acetic acid, 2: 1-hydroxy-2-propanone, 3: furfural, 4: 5-(Hydroxymethyl)dihydro2(3H)-furanone, 5: guaiacol, 6: creosol, 7: vinylguaiacol, 8: syringol, 9: isoeugenol, 10: levoglucosan, 11: vinylsyringol, 12: propenylsyringol).

\subsubsection{Catalytic Pyrolysis of CoOak and WPFs}

Figure 3 presents the TMR-GC/MS chromatograms obtained from the in situ CFP of CoOak, WPFs, CoOak/WPFs over HBeta(25). As shown in Figure 3a, the chromatogram for the CFP of CoOak contained the peaks for light hydrocarbons $\left(<\mathrm{C}_{4}\right)$ and aromatic hydrocarbons. On the other hand, peaks for oxygen containing compounds were not detected, which indicates that the efficient catalytic conversion of oxygen-containing pyrolyzates of CoOak to light hydrocarbons and aromatic hydrocarbons can be achieved using HBeta(25). The hydrocarbon pool mechanism is known as the major reaction pathways for the formation of aromatic hydrocarbons from biomass over acid zeolite catalysts [31]. Typical pyrolyzates of woody biomass, consisting of acids, furans, levoglucosan, aldehydes, and phenols, can be converted to light hydrocarbons, mainly olefins, via a catalytic dehydration, decarboxylation, and decarbonylation reaction over the catalyst. These light hydrocarbons form a hydrocarbon pool and produce aromatic hydrocarbons via an additional aromatization reaction. In this step, the acidity, pore size, and pore structure are the most important factors affecting the overall reaction efficiency. 


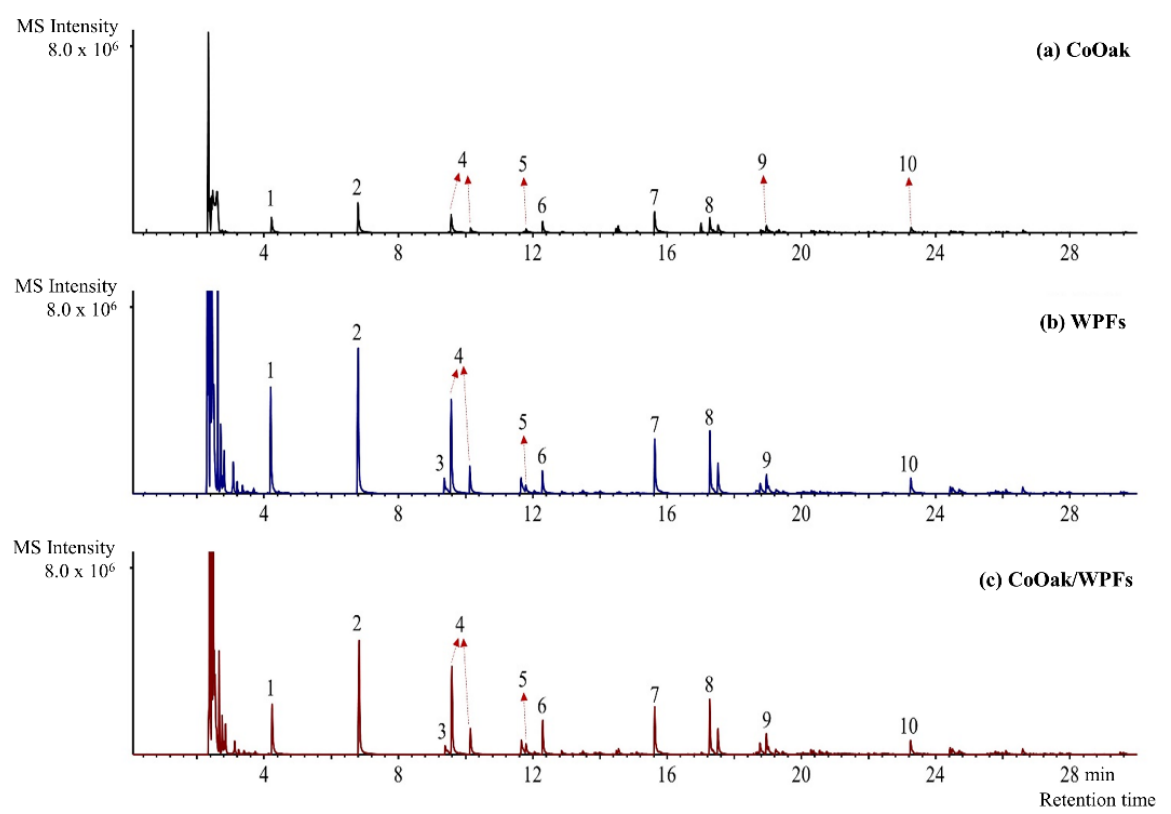

Figure 3. Pyrograms obtained from catalytic pyrolysis of (a) Cork Oak; (b) WPFS; and (c) Cork Oak/WPFS over HBeta(25). (1: benzene, 2: toluene, 3: ethylbenzene, 4: xylenes, 5: ethyltoluene, 6: trimethylbenzene, 7: naphthalene, 8: methylnaphthalene, 9: anthracene, 10: pyrene).

Although large amounts of aromatic hydrocarbons were produced by the CFP of CoOak, much higher peak intensities for aromatic hydrocarbons were observed on the TMR-GC/MS chromatogram for the CFP of WPFs, as shown in Figure 3b. This can be explained by the pyrolyzates of WPFs. Although small amounts of oxygen-containing pyrolyzates were observed on the pyrogram of WPFs (Figure 2b), most of the pyrolyzates of WPFs consisted of hydrocarbons, which can be divided into alkanes, alkenes, alkadienes, and aromatic hydrocarbons. These hydrocarbons can be converted to light hydrocarbons over the HBeta(25) catalyst and finally produce aromatic hydrocarbons via a hydrocarbon pool mechanism [32]. Larger amounts of aromatic hydrocarbon formation from WPFs also can be explained by the lower contents of oxygen-containing pyrolyzates in WPFs than CoOak. The formation efficiency of aromatic hydrocarbons from polymer materials can be expected with their effective hydrogen to carbon ratio $\left(\mathrm{H} / \mathrm{C}_{\text {eff }}\right.$ ). The $\mathrm{H} / \mathrm{C}_{\text {eff }}$ ratios of PS, PP, and HDPE, which are the main components of WPFs, were much higher than that of CoOak. This suggests that much larger amounts of aromatic hydrocarbons can be produced from the CFP of WPFs than that of CoOak. Although the summed amount of char and ash in WPFs was larger than that in CoOak (Table 1), the CFP of CoOak produced the larger amount of solid residue (36.8 wt \%) than that of WPFs $(22.0 \mathrm{wt} \%)$. This indicates that the CFP of CoOak produces a larger amount of coke than that of WPFs over HBeta(25). The high coke yield during the CFP of biomass has been reported by other researchers [33]. They explained that oxygen-containing pyrolyzates can be converted to coke more easily than hydrocarbons. For example, phenols, the main pyrolyzates of lignin, can produce large amounts of coke due to their oligomerization inside the pores of the catalysts. Resasco et al. [34] indicated that the formation of coke from the lignin over acid zeolites occurs via a "phenolic pool mechanism".

Table 1. The yields of aromatic hydrocarbons obtained from the catalytic pyrolysis of CoOak, WPFs, and their mixture (Unit: wt \%).

\begin{tabular}{cccc}
\hline \multirow{2}{*}{ Cork Oak } & \multirow{2}{*}{ WPFs } & \multicolumn{2}{c}{ CoOak/WPFs } \\
\cline { 3 - 4 } & & Theoretical Value & Experimental Value \\
\hline 2.90 & 11.75 & 7.31 & 7.85 \\
\hline
\end{tabular}


Figure $3 \mathrm{c}$ shows the TMR-GC/MS chromatogram obtained from the CFCP of CoOak and WPFs over HBeta(25). Interestingly, the experimental yields of aromatic hydrocarbons obtained from the CFCP of CoOak and WPFs were larger than their calculated values derived from the respective experimental yields obtained from the CFP of CoOak and WPFs over HBeta(25) (Table 1). This indicates that the synergistic effect on the production of aromatic hydrocarbons can be achieved by applying a mixture of CoOak and WPFs as a sample for catalytic pyrolysis over HBeta(25). Figure 4 shows the possible reaction pathway on the formation of aromatic hydrocarbons during the CFCP of CoOak and WPFs over HBeta(25). The effects of cofeeding WPFs as a hydrogen donor to CoOak and the effective Diels-Alder reaction between the pyrolyzates of CoOak and WPFs can be explained as the main reaction mechanism enhancing the synergistic formation of aromatic hydrocarbons [35]. The effective hydrocarbon pool formation due to the strong acidity and appropriate pore size of HBeta(25) play an important role in the increased production of aromatic hydrocarbons. Owing to the three dimensional structure and pore size of the HBeta catalyst, the products obtained from the catalytic pyrolysis of biomass over HBeta has higher selectivity for aromatic hydrocarbons [36,37]. An additional Diels-Alder reaction between the furans and light olefins also can produce aromatic hydrocarbons over the HBeta catalyst [38], as depicted in Figure 4. Although HBeta can produce large amounts of coke during the CFP of biomass [20], the experimental yield of solid residue obtained from the CFCP of CoOak and HDPE (26.4 wt \%) was lower than the calculated yield (29.4 wt \%). This indicates that the coke amount also can be decreased by applying the CFCP of CoOak and HDPE. The lower coke formation due to CFCP can be explained as the efficient Diels-Alder reaction between the pyrolyzates of biomass and plastics. The conversion of oxygen containing pyrolyzates, such as furans, to coke by their oligomerization reaction can be reduced because the conversion to aromatic hydrocarbons can be increased by the efficient Diels-Alder reaction between the pyrolyzates of biomass and plastics. This effective Diels-Alder reaction can act as an inhibition factor for the formation of coke. Reduced coke accumulation is a very important factor because the total life time of the catalyst can be extended by reducing the amount of accumulated coke [39].

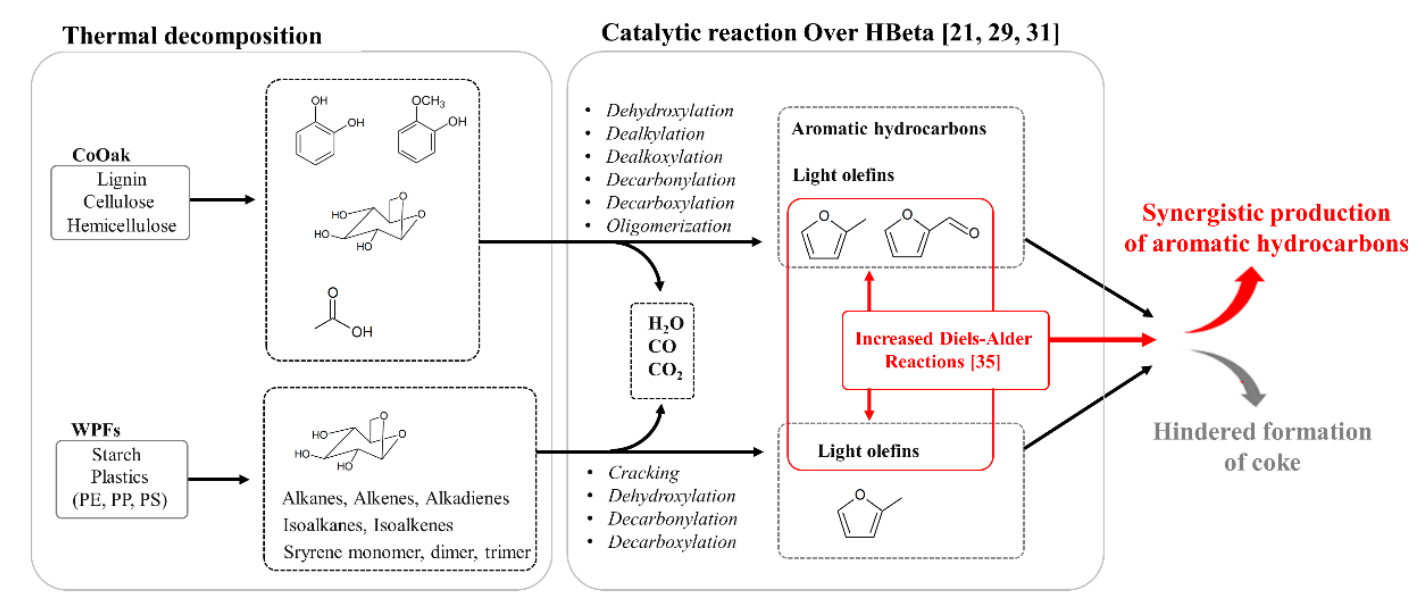

Figure 4. Possible reaction pathway for the synergistic formation of aromatic hydrocarbons during the CFCP of CoOak and WPFs over HBeta(25).

\section{Materials and Methods}

\subsection{CoOak and WPFs}

CoOak powder, which was obtained from the Korean native oak tree, was sieved to a particle size smaller than $500 \mu \mathrm{m}$. WPFs, which was emitted as municipal waste in Seoul city, was cut to make a film size lower than $1 \mathrm{~mm}^{2}$. Both CoOak and WPFs were dried at $80^{\circ} \mathrm{C}$ for $6 \mathrm{~h}$ and kept in a desiccator before each experiment. Table 2 lists the proximate and ultimate analysis results of CoOak 
and WPFs. Both CoOak and WPFs had large amounts of volatiles and fixed carbon $[24,39]$. Compared to CoOak, WPFs had a higher ash content. As expected, WPFs had a high C (64.2\%) and O (25.4\%) content. This indicates that a considerable amount of WPFs contained a biopolymer with biomass in its structure and/or PET having oxygen as one of its main elements. The higher $\mathrm{C}$ and $\mathrm{H}$ content of WPFs than CoOak suggests that WPFs can act as hydrogen donor to CoOak during the catalytic copyrolysis reaction.

Table 2. Physicochemical characteristics of CoOak and WPFs.

\begin{tabular}{cccc}
\hline Sample & & CoOak [39] & WPFs [24] \\
\hline & Water & 2.5 & 1.3 \\
& Volatiles & 81.1 & 80.8 \\
Proximate analysis & Fixed carbon & 15.1 & 11.6 \\
& Ash & 1.3 & 6.3 \\
& Sum & 100 & 100 \\
\hline \multirow{3}{*}{ Ultimate analysis $^{\text {a }}$} & $\mathrm{C}$ & 46.3 & 64.3 \\
& $\mathrm{H}$ & 5.9 & 9.8 \\
& $\mathrm{O}$ & 47.4 & 25.4 \\
& $\mathrm{~N}$ & 0.4 & 0.5 \\
& $\mathrm{~S}$ & - & - \\
\hline
\end{tabular}

${ }^{\mathrm{a}}$ On a dry basis, ${ }^{\mathrm{b}}$ By difference.

\subsection{Catalyst}

HBeta(25) was purchased from Zeolyst International. According to the specification sheet supplied by the manufacturer, HBeta(25) had a pore size of $0.74 \mathrm{~nm}$ and Brunauer-Emmett-Teller (BET) surface area of $780 \mathrm{~m}^{2} / \mathrm{g}$. $\mathrm{NH}_{3}$-TPD curve of HBeta(25), as shown in Figure 5, which indicates that HBeta (25) has strong acidity.

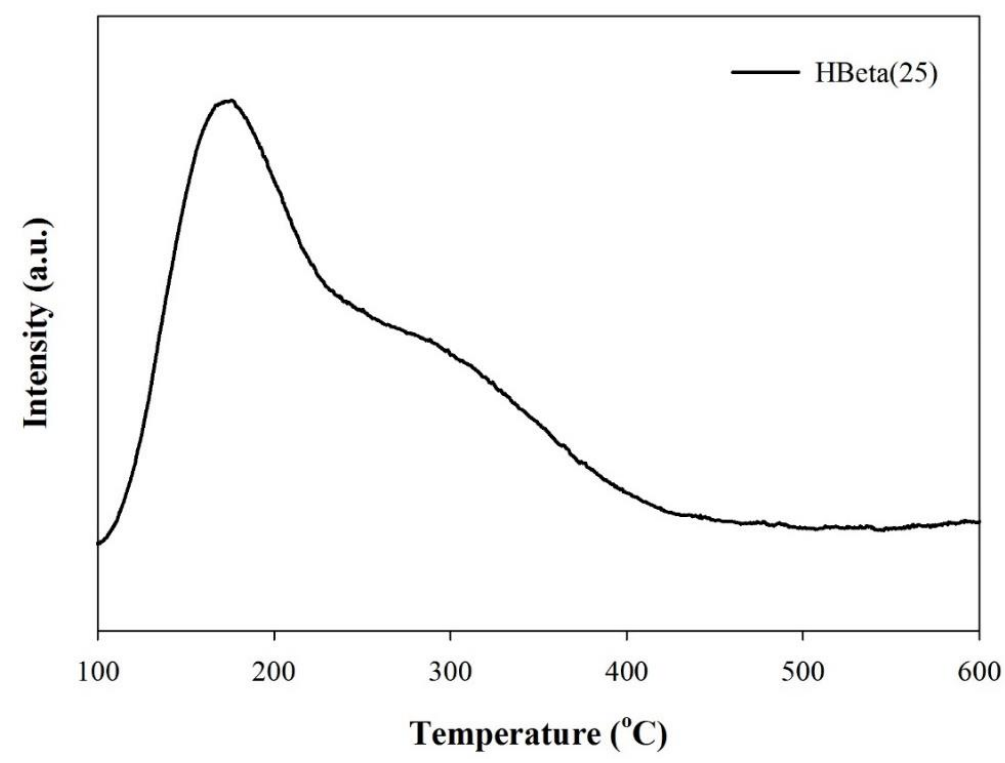

Figure 5. $\mathrm{NH}_{3}-\mathrm{TPD}$ profiles of $\operatorname{HBeta}(25)$.

\subsection{TG Analysis}

The same amount (4 mg) of CoOak, WPFs, and their mixture (CoOak/WPFs: $1 / 1$ ) were heated non-isothermally from ambient temperature to $800^{\circ} \mathrm{C}$ at $20^{\circ} \mathrm{C} / \mathrm{min}$ under nitrogen atmosphere in a 
TG analyzer (Pyris Diamond, Perkin Elmer, Inc., San Diego, MA, USA). For catalytic pyrolysis, 4 mg of HBeta(25) was also blended with the sample and the same TG analysis conditions were applied.

\subsection{TMR-GC/MS Analysis}

TMR-GC/MS (RX-3050TR, Frontier Laboratories Ltd., Fukushima, Japan; 7890A/5975C inert, Agilent technology, Santa Clara, CA, USA; Supplementary Materials Figure S2) was used for the iso-thermal and CFP together with their product analysis. For non-catalytic pyrolysis, $1 \mathrm{mg}$ of CoOak, WPFs, and their mixture (CoOak/WPFs: $1 / 1)$ were pyrolyzed in a microreactor at $600{ }^{\circ} \mathrm{C}$ by free-falling the sample cup into a preheated furnace. In the case of CFP, $5 \mathrm{mg}$ of HBeta(25) was also mixed together with $1 \mathrm{mg}$ of sample (Catalyst/Sample: 5/1). The product vapor was transferred to a separation column and cryo-focused at the front part of the column by liquid nitrogen $\left(-195{ }^{\circ} \mathrm{C}\right)$ using Micro-Jet Cryo Trap (MJT-1030E, Frontier Laboratory Ltd., Fukushima, Japan) via GC inlet. After a sufficient reaction time ( $3 \mathrm{~min}$ ), the chemicals cryo-focused inside the column were vaporized by shutting off the liquid nitrogen supply and GC oven heating program. The separated chemicals were detected by MS. Each peak on the MS chromatogram was identified using MS libraries (NIST 8th; National Institute of Standard and Technology, Gaithersburg, MD, USA and F-search; Frontier Laboratory Ltd., Fukushima, Japan). The MS peak area for each product was integrated to compare its product selectivity. External standard (ESTD) calibration for aromatic hydrocarbons was also performed with the MS peak area to quantify the yields of aromatic hydrocarbons. The ESTD calibration curves for each aromatic hydrocarbon was made by analyzing the different amounts of aromatic hydrocarbon standard mixture. Table S1 summaries the detailed TMR-GC/MS operation conditions.

\section{Conclusions}

The effectiveness of WPFs and HBeta(25) as a hydrogen donating cofeeding material and catalyst, respectively, on the CFP of CoOak was demonstrated. By applying the CFCP of CoOak and WPFs over HBeta(25), the thermal decomposition temperature of CoOak and WPFs shifted to a lower temperature than their individual CFP reactions due to the effective interaction between the pyrolysis intermediates, and the use of HBeta(25) having strong acidity and appropriate pore size. The synergistic effect on the formation of aromatic hydrocarbons and the decrease of coke were also enhanced by applying the CFCP of CoOak and WPFs due to the increased hydrocarbon pool mechanism, which can increase the Diels-Alder reaction between the pyrolysis intermediates of CoOak and WPFs.

Supplementary Materials: The following are available online at http:/ /www.mdpi.com/2073-4344/8/8/318/s1, Figure S1: DTG curve of HDPE at a heating rate of $20^{\circ} \mathrm{C} / \mathrm{min}$, Figure S2: Schematic diagram for TMR-GC/MS applied for thermal and catalytic pyrolysis at $600^{\circ} \mathrm{C}$, Table S1: Detailed TMR-GC/MS conditions.

Author Contributions: Conceptualization, Y.-K.P. and Y.-M.K.; Data curation, J.Y.L.; S.K. and T.U.H.; Formal analysis, B.L.; Investigation, B.L. and A.W.; Methodology, A.W.; Supervision, Y.-M.K.; Validation, H.W.L. and S.K.; Visualization, T.U.H.; Writing—original draft, Y.-K.P.; Writing—review \& editing, Y.-M.K.

Funding: This research is supported by the "R\&D Center for reduction of Non- $\mathrm{CO}_{2}$ Greenhouse gases (2016001690005)" funded by Korea Ministry of Environment (MOE) as “Global Top Environment R\&D Program"

Conflicts of Interest: The authors declare no conflicts of interest

\section{References}

1. Lee, H.; Park, R.S.; Lee, H.W.; Hong, Y.; Lee, Y.; Park, S.H.; Jung, S.-C.; Yoo, K.-S.; Jeon, J.-K.; Park, Y.-K. Adsorptive removal of atmospheric pollutants over Pyropia tenera chars. Carbon Lett. 2016, 19, 79-88. [CrossRef]

2. Cha, J.S.; Park, S.H.; Jung, S.-C.; Ryu, C.; Jeon, J.-K.; Shin, M.-C.; Park, Y.-K. Production and utilization of biochar: A review. J. Ind. Eng. Chem. 2016, 40, 1-15. [CrossRef]

3. Kim, Y.-M.; Han, T.U.; Hwang, B.; Lee, B.; Lee, H.W.; Park, Y.-K.; Kim, S. Pyrolysis kinetics and product properties of softwoods, hardwoods, and the nut shell of softwood. Korean J. Chem. Eng. 2016, 33, 2350-2358. [CrossRef] 
4. Lee, Y.; Shafaghat, H.; Kim, J.; Jeon, J.-K.; Jung, S.-C.; Lee, I.-G.; Park, Y.-K. Upgrading of pyrolysis bio-oil using $\mathrm{WO}_{3} / \mathrm{ZrO}_{2}$ and Amberlyst catalysts: Evaluation of acid number and viscosity. Korean J. Chem. Eng. 2017, 34, 2180-2187. [CrossRef]

5. Lee, H.; Kim, Y.-M.; Lee, I.-G.; Jeon, J.-K.; Jung, S.-C.; Chung, J.D.; Choi, W.G.; Park, Y.-K. Recent advances in the catalytic hydrodeoxygenation of bio-oil. Korean J. Chem. Eng. 2016, 33, 3299-3315. [CrossRef]

6. Lee, S.; Kim, T.; Kang, K. Performance and emission characteristics of a diesel engine operated with wood pyrolysis oil. Proc. Inst. Mech. Eng. D J. Automob. Eng. 2014, 228, 180-189. [CrossRef]

7. Kim, Y.-M.; Kim, B.-S.; Chea, K.-S.; Jo, T.S.; Kim, S.; Park, Y.K. Ex-Situ catalytic pyrolysis of Korean native oak tree over microporous zeolites. Appl. Chem. Eng. 2016, 27, 407-414. [CrossRef]

8. Mochizuki, T.; Chen, S.-Y.; Toba, M.; Yoshimura, Y. Pyrolyzer-GC/MS system-based analysis of the effects of zeolite catalysts on the fast pyrolysis of Jatropha husk. Appl. Catal. A 2013, 10, 174-181. [CrossRef]

9. Rezaei, P.S.; Shafaghat, H.; Daud, W.M.A.W. Aromatic hydrocarbon production by catalytic pyrolysis of palm kernel shell waste using a bifunctional Fe/HBeta catalyst: Effect of lignin-derived phenolics on zeolite deactivation. Green Chem. 2016, 18, 1684-1693. [CrossRef]

10. Antonakou, E.; Lappas, A.; Nilsen, M.H.; Bouzga, A.; Stöcker, M. Evaluation of various types of Al-MCM-41 materials as catalysts in biomass pyrolysis for the production of bio-fuels and chemicals. Fuel 2006, 85, 2202-2212. [CrossRef]

11. Hassan, H.; Lim, J.K.; Hameed, B.H. Recent progress on biomass co-pyrolysis conversion into high-quality bio-oil. Bioresour. Technol. 2016, 221, 645-655. [CrossRef] [PubMed]

12. Dorado, C.; Mullen, C.A.; Boateng, A.A. H-ZSM5 catalyzed co-pyrolysis of biomass and plastics. ACS Sustain. Chem. Eng. 2014, 2, 301-311. [CrossRef]

13. Al-Salem, S.M.; Antelava, A.; Constantinou, A.; Manos, G.; Dutta, A. A review on thermal and catalytic pyrolysis of plastic solid waste (PSW). J. Environ. Manag. 2017, 197, 177-198. [CrossRef] [PubMed]

14. Ouadi, M.; Jaeger, N.; Greenhalf, C.; Santos, J.; Conti, R.; Hornung, A. Thermo-catalytic reforming of municipal solid waste. Waste Manag. 2017, 68, 198-206. [CrossRef] [PubMed]

15. Zhang, X.; Lei, H.; Chen, S.; Wu, J. Catalytic co-pyrolysis of lignocellulosic biomass with polymers: A critical review. Green Chem. 2016, 18, 4145-4169. [CrossRef]

16. Jae, J.; Tompsett, G.A.; Foster, A.J.; Hammond, K.D.; Auerbach, S.M.; Lobo, R.F.; Huber, G.W. Investigation into the shape selectivity of zeolite catalysts for biomass conversion. J. Catal. 2011, 279, 257-268. [CrossRef]

17. Marcilla, M.; Gómez-Siurana, A.; Odjo, A.O.; Navarro, R.; Berenger, N.D. Characterization of vacuum gas oil-low density polyethylene blends by thermogravimetric analysis. Polym. Degrad. Stab. 2008, 93, 723-730. [CrossRef]

18. Sirous-Rezaei, P.; Jae, J.; Ha, J.-M.; Ko, C.H.; Kim, J.M.; Jeon, J.K.; Park, Y.-K. Mild hydrodeoxygenation of phenolic lignin model compounds over a FeReOx $/ \mathrm{ZrO}_{2}$ catalyst: Zirconia and rhenium oxide as efficient dehydration promoters. Green Chem. 2018, 20, 1472-1483. [CrossRef]

19. Han, T.U.; Kim, Y.-M.; Watanabe, C.; Teramae, N.; Park, Y.-K.; Kim, S.; Lee, Y. Analytical pyrolysis properties of waste medium-density fiberboard and particle board. J. Ind. Eng. Chem. 2015, 32, 245-352. [CrossRef]

20. Kim, B.-S.; Kim, Y.-M.; Jae, J.; Watanabe, C.; Kim, S.; Jung, S.-C.; Kim, S.C.; Park, Y.-K. Pyrolysis and catalytic upgrading of Citrus unshiu peel. Bioresour. Technol. 2015, 194, 312-319. [CrossRef] [PubMed]

21. Kim, Y.-M.; Kim, S.; Han, T.U.; Park, Y.-K.; Watanabe, C. Pyrolysis reaction characteristics of Korean pine (Pinus Koraiensis) nut shell. J. Anal. Appl. Pyrolysis 2014, 110, 435-441. [CrossRef]

22. Kim, Y.-M.; Jae, J.; Kim, B.-S.; Hong, Y.; Jung, S.-C.; Park, Y.-K. Catalytic co-pyrolysis of torrefied yellow poplar and high-density polyethylene using microporous HZSM-5 and mesoporous Al-MCM-41 catalysts. Energy Convers. Manag. 2017, 149, 966-973. [CrossRef]

23. Vega, D.; Villar, M.A.; Failla, M.D.; Vallés, E.M. Thermogravimetric analysis of starch-based biodegradable blends. Polym. Bull. 1996, 37, 229-235. [CrossRef]

24. Kim, Y.-M.; Lee, B.; Han, T.U.; Kim, S.; Yu, T.-U.; Bang, B.Y.; Kim, J.-S.; Park, Y.-K. Research on pyrolysis properties of waste plastic films. Appl. Chem. Eng. 2017, 28, 23-28.

25. Yu, J.; Sun, L.; Ma, C.; Qiao, Y.; Yao, H. Thermal degradation of PVC: A review. Waste Manag. 2016, 48, 300-314. [CrossRef] [PubMed]

26. Oromiehie, A.R.; Taherzadeh lari, T.; Rabiee, A. Physical and thermal mechanical properties of corn starch/LDPE composites. Appl. Polym. 2013, 127, 1128-1134. [CrossRef] 
27. El-Sabbagh, A. Effect of coupling agent on natural fibre in natural fibre/polypropylene composites on mechanical and thermal behaviour. Compos. B Eng. 2014, 57, 126-135. [CrossRef]

28. Garcia-Garcia, D.; Carbonell-Verdu, A.; Jordá-Vilaplana, A.; Balart, R.; Garcia-Sanoguera, D. Development and characterization of green composites from bio-based polyethylene and peanut shell. Appl. Polym. 2016, 133, 43940. [CrossRef]

29. Marcilla, A.; Go'mez-Siurana, A.; Valde's, F. Catalytic pyrolysis of LDPE over H-beta and HZSM-5 zeolites in dynamic conditions Study of the evolution of the process. J. Anal. Appl. Pyrolysis 2007, 79, 433-442. [CrossRef]

30. Patwardhan, P.R.; Satrio, J.A.; Brown, R.C.; Shanks, B.H. Product distribution from fast pyrolysis of glucose-based carbohydrates. J. Anal. Appl. Pyrolysis 2009, 86, 323-330. [CrossRef]

31. Kim, B.-S.; Kim, Y.-M.; Lee, H.W.; Jae, J.; Kim, D.H.; Jung, S.-C.; Watanabe, C.; Park, Y.-K. Catalytic copyrolysis of cellulose and thermoplastics over HZSM-5 and HY. ACS Sustain. Chem. Eng. 2016, 4, 1354-1363. [CrossRef]

32. Li, X.; Zhang, H.; Li, J.; Su, L.; Zuo, J.; Komarneni, S.; Wang, Y. Improving the aromatic production in catalytic fast pyrolysis of cellulose by co-feeding low-density polyethylene. Appl. Catal. A Gen. 2013, 455, 114-121. [CrossRef]

33. Hong, Y.; Lee, Y.; Rezaei, P.S.; Kim, B.-S.; Jeon, J.-K.; Jae, J.; Jung, S.-C.; Kim, S.C.; Park, Y.-K. In-Situ catalytic copyrolysis of cellulose and polypropylene over desilicated ZSM-5. Catal. Today 2017, 293-294, 151-158. [CrossRef]

34. To, A.T.; Resasco, D.E. Role of a phenolic pool in the conversion of m-cresol to aromatics over HY and HZSM-5 zeolites. Appl. Catal. A Gen. 2014, 487, 62-71. [CrossRef]

35. Xue, Y.; Kelkar, A.; Bai, X. Catalytic co-pyrolysis of biomass and polyethylene in a tandem micropyrolyzer. Fuel 2016, 166, 227-236. [CrossRef]

36. Aho, A.; Kumar, N.; Eränen, K.; Salmi, T.; Hupa, M.; Murzin, D.Y. Catalytic pyrolysis of woody biomass in a fluidized bed reactor: Influence of the zeolite structure. Fuel 2008, 87, 2493-2501. [CrossRef]

37. Widayatno, W.B.; Guan, G.; Rizkiana, J.; Du, X.; Hao, X.; Zhang, Z.; Abudula, A. Selective catalytic conversion of bio-oil over high-silica zeolites. Bioresour. Technol. 2015, 179, 518-523. [CrossRef] [PubMed]

38. Cheng, Y.-T.; Huber, G.W. Production of targeted aromatics by using Diels-Alder classes of reactions with furans and olefins over ZSM-5. Green Chem. 2012, 14, 3114-3125. [CrossRef]

39. Lee, Y.; Oh, D.; Kim, Y.-M.; Jae, J.; Jung, S.-C.; Jeon, J.-K.; Kim, S.C.; Park, Y.-K. Catalytic copyrolysis of cork oak and bio-oil distillation residue. Appl. Surf. Sci. 2018, 429, 95-101. [CrossRef] 